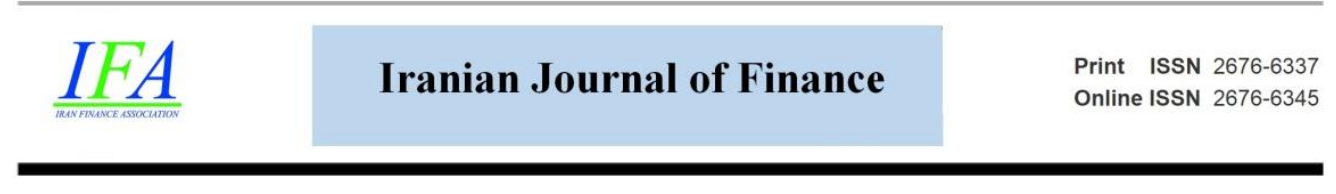

\title{
Investigation of the Effect of Behavioral and Macroeconomic Factors on the Volatility of Tehran Stocks Market: FIAPGARCH-X
}

\section{Mahmoud Goudarzi}

Ph.D. Candidate in Financial Management, Faculty of Management, Qazvin Branch, Islamic Azad university, Qazvin, Iran. (Email: tmgoodarzi@gmail.com)

\section{Amir Mohammadzadeh*}

*Corresponding Author, Associate Prof., Department of Financial Management, Qazvin Branch, Islamic Azad University, Qazvin, Iran. (Email: A.Mohammadzadeh@qiau.ac.ir)

\section{Mohsen Seighali}

Associate Prof., Department of Financial Management, Qazvin Branch, Islamic Azad University, Qazvin, Iran. (Email: mohsenseighali@qiau.ac.ir)

Document Type: Original Article

Received: 2021/03/15

Accepted: 2021/09/01
2022, Vol. 6, No. 1. 28-53.

Published: 2022/02/09

\begin{abstract}
One of the characteristics of the financial market, especially the stock market, is the effects of behavioral factors and on other financial and non-financial markets. There are several factors that affect the return of a stock exchange. We can refer to political, socio-cultural, technological and finally economic factors. A stock market is an economic market in which securities are traded under specific rules and regulations. Accordingly, in this study, the effect of behavioral financial arguments and other financial markets on stock market returns based on quantitative analysis has been studied. This article tries to examine how exchange rates, gold, and oil as key factors of a model can
\end{abstract}


explain fluctuations of the stock market index. so the effect of those variables on the stock market index in the period 2008 to the first six months of 2018 has been analyzed using the FIAPGARCH-X model. The results of the analysis show that the effect of exchange rates on the stock market fluctuations is greater than the other two factors. The results also indicate that there are asymmetric effects of increased returns on the stock market, which is consistent with behavioral bias in behavioral finance.

Keywords: volatility spillover, behavioral finance, FIAPGARCH

DOI: https://doi.org/10.30699/IJF.2022.255430.1167 Publisher: Iran Finance Association

Copyright: author(s) Type of License: Creative Commons License (CC-BY 4.0)

\section{Introduction}

Contrary to popular belief in modern financial theory which states that decision-makers behave quite rationally to seek to maximize their profits, studies conducted in the field of the financial-behavioral show that the human decision-making process is not completely logical and not based on complete information, but the decision-maker uses mental shortcuts in the process which can also lead to useless decisions (Kian, 2013). Most of the time, financialbehavioral factors examine the decision-making processes of the investors' perceptions and their reactions to different financial market conditions, and they mostly emphasize on the impact of personality, investors' cultures and judgments based on investment decisions. Knowing the behavioral biases makes the investors more aware of their decision-making process, and if faced with biases, they can react well and avoid deviations in decision making (Abdolrahimian et al, 2018). This article, using financial-behavioral teachings of gold, oil, and foreign exchange, attempts to analyze the fluctuations of stock market returns. To do that, the present study, using advanced models in fluctuations, has analyzed the market investment's behavior of the stock market. This article seeks to examine whether there exist any behavioral biases, including the asymmetric effect of fluctuations (as a proxy of the behavior of stock market participants) in the behavior of stock market's investors or not. The present article is organized into five sections.

In the second part, the literature and the background of studies have been expressed in two parts namely Domestic and Foreign studies. In the third part, the methodology of the model has discussed. In the next section data and 
analysis of the results are presented. Finally, the last part of the article is devoted to concluding and making suggestions.

\section{Literature Review}

\section{Theoretical Foundations}

The 1980s were a time of important academic discussion of the consistency of the efficient markets model for the aggregate stock market with econometric evidence about the time-series properties of prices, dividends and earnings. Of particular concern was whether these stocks show excess volatility relative to what would be predicted by the efficient markets model. The anomalies that had been discovered might be considered at worst small departures from the fundamental truth of market efficiency, but if most of the volatility in the stock market was unexplained, it would call into question the basic underpinnings of the entire efficient markets theory. The anomaly represented by the notion of excess volatility seems to be much more troubling for efficiency markets theory than some other financial anomalies, such as the January effect or the day-of-the-week effect. The volatility anomaly is much deeper than those represented by price stickiness or tatonnement or even by exchange-rate overshooting. The evidence regarding excess volatility seems, to some observers at least, to imply that changes in prices occur for no fundamental reason at all, that they occur because of such things as "sunspots" or "animal spirits" or just mass psychology (Shiller,2003).

Academic finance has evolved a long way from the days when the efficient markets theory was widely considered to be proved beyond doubt. Behavioral finance - that is, finance from a broader social science perspective including psychology and sociology - is now one of the most vital research programs, and it stands in sharp contradiction to much of efficient markets theory.

In the 1990s, a lot of the focus of academic discussion shifted away from these econometric analyses of time series on prices, dividends and earnings toward developing models of human psychology as it relates to financial markets. The field of behavioral finance developed. Researchers had seen too many anomalies, too little inspiration that our theoretical models captured important fluctuations.

The collaboration between finance and other social sciences that has become known as behavioral finance has led to a profound deepening of our knowledge of financial markets. In judging the impact of behavioral finance to 
date, it is important to apply the right standards. Of course, we do not expect such research to provide a method to make a lot of money off of financial market inefficiency very fast and reliably. We should not expect market efficiency to be so egregiously wrong that immediate profits should be continually available. But market efficiency can be egregiously wrong in other senses. For example, efficient markets theory may lead to drastically incorrect interpretations of events such as major stock market bubbles.

Eugene Fama (1998) found fault for two basic reasons. The first was that the anomalies that were discovered tended to appear to be as often underreaction by investors as an overreaction. The second was that the anomalies tended to disappear, either as time passed or as the methodology of the studies improved. His first criticism reflects an incorrect view of the psychological underpinnings of behavioral finance. Since there is no fundamental psychological principle that people tend always to overreact or always to underreact, it is no surprise that research on financial anomalies does not reveal such a principle either. His second criticism is also weak. It is the nature of scholarly research, at the frontier, in all disciplines, that initial claims of important discoveries are often knocked down by later research. The most basic anomaly, of excess volatility, seems hard to have been knocked down, and it is in fact graphically reinforced by the experience of the past few years in the stock markets of the world. Moreover, the mere fact that anomalies sometimes disappear or switch signs with time is no evidence that the markets are fully rational. That is also what we would expect to see happen even in highly irrational markets. Even the basic relation suggested by market inefficiency, that stocks whose price is bid up by investors will tend to go back down later, and stocks that are underpriced by investors will tend to go up later, is not a relationship that can be easily tested or that should hold in all time periods. The fundamental value of stocks is hard to measure, and, moreover, if speculative bubbles (either positive bubbles or negative bubbles) last a long time, then even this fundamental relation may not be observed except in very long sample periods.

Behavioral finance explains the empirical evidence suggesting that the poor descriptive power of some current financial models stems from the fact that financial asset prices arise from a statistically complex and nonlinear process. Peters (1994) noted that stock prices and returns are cyclical, imperfectly predictable in the short run, and unpredictable in the long run and that they exhibit nonlinear, and possibly chaotic, behavior related to timevarying positive feedback. Also, decision-makers who overweight more recent evidence, tend to be improperly regressive, overweight the value of consensus 
beliefs, seek confirming evidence and wish to be part of the group, all of which encourage positive feedback. Baumol noted that, given the complexity of stock evaluation, decision-makers will end up focusing on similar pieces of information, called focal points. This behavior, coupled with the fact that new stock supply tends to be relatively inelastic in the short run, tends to exacerbate positive-feedback effects. The observation that stock-price breaks are more severe than upward adjustments is also consistent with investors being loss averse, tending to focus on negative information when under stress, overweighting the probability of negative events, and becoming more lossaverse as downward movements in the value of their portfolios remind them of their incomplete personal control (Olsen,1998). Abolafia (1996) demonstrated how professional investment managers might encourage positive feedback as a result of acceptance of and commitment to a common institutional culture, set of beliefs, and practices. Neoclassical economic models assume that negative feedback always dominates, however, and that prices tend toward stability. These assumptions explain why current financial models, based on stable equilibriums, tend to do poorly, especially in times of financial market upheaval when uncertainty is great and positive feedback is likely to become prominent. The discovery of nonlinearity in security prices and the fact that outcomes can be predicted only within wide limits also have normative implications for financial decision making. In particular, Hammond (1996) noted that optimization strategies tend to be brittle, in that when they fail, they create a greater variance in outcomes than more robust satisficing strategies. Therefore, given imperfect market predictability, to avoid catastrophe, investors might prefer to use decision processes that preserve appropriate future financial flexibility. Empirical evidence indicates that investors do attempt this approach, but the ways they do it can be improved with education and training.

Behavioral finance also appears to offer an explanation for what some observers label excessive stock-price volatility. In the lively debate going on among academics (White 1990) about whether stock prices exhibit excessive volatility, the bogey is a price based on underlying concepts of present value, rational economic man, and market efficiency. Reliable evidence of excessive volatility is scarce because empirical tests using market data imply that researchers have some knowledge of the (unknowable) valuation model used by investors and because experimental market investigations assume similar investor behaviors in synthetic and in real markets. But financial economists appear to agree that security-price volatility and trading volume should vary directly with the divergence of investor opinion (Schwartz, 1988). At this 
point, standard finance is unable to explain a wide divergence of opinion except to invoke the concept of asymmetrical information. In public markets for widely traded securities, however, where asymmetries are likely to be small, it seems unlikely that differential information among investors could create the kind of divergence of opinion necessary to account for many instances of high stock-price volatility. Behavioral finance offers a second source of opinion difference. This source originates in the decision processes investors use to manipulate data and arrive at estimates of securities' values. As noted in Payne (1993), research supports the notion that an investor's decision process is adaptive to the perceived nature of the problem and the environment in which the problem is framed. In particular, studies have documented that, despite appearing to be minor, differences in the perceived complexity of a decision, in the decision maker's emotional state, in the time available to make the decision, in the reversibility of the decision, and even in the format of the presented information have important influences on the process used to arrive at a decision. As a result of the adaptive nature of the decision process itself, even if all investors were presented with the same set of data, differences in data perception, selection, weighting, and manipulation would prevail. If the decision process is adaptive, market volatility will not only vary directly with information asymmetry but will also be greater in situations characterized by a greater difference in decision processes. Because of the complexity of stock selection, the decision process is likely to vary widely among investors. In particular, stock valuation appears to be the quintessential complex, illstructured task. "Complex, ill-structured tasks," as they are formally called, dominate in the social sciences. Such tasks are characterized ex-ante by a lack of a unique set of characteristics that clearly define the method and information needed to arrive at a single, well-defined goal. Such tasks are also usually distinguished by statistical overdetermination (in which too many variables are present relative to the number of pieces of data), low base rates of occurrence, and ambiguous antecedent behavior states (that is, a lack of clarity about the conditions before the phenomenon was described). Ex post, the performance of few "experts" on complex, ill-structured tasks surpasses naive strategies, and when the experts do outperform, the margin of superior performance is small and inconsistent(Olsen,1998). The majority of empirical studies of the performance of professional investment managers report just such results. Finally, a survey of the current literature on security analysis and portfolio management clearly identifies a large number of techniques and a wide range of opinions that exist among investment professionals concerning approaches to stock valuation. Complex, ill-structured tasks or decisions give rise to great variability in decision outcomes because they tend to lie more toward the 
experiential or intuitive end of the decision spectrum than the objective end and make greater use of idiosyncratic information and procedures that are personal, concrete, holistic, affective (emotional), and based on such associative conventions as the use of analogies and stereotypes (Busemeyer,1995). In addition, because the information is both qualitative and quantitative, "stories" are often constructed to achieve integration and to evaluate the coherence and completeness of a proposed decision or forecast. Payne suggested that decision-makers tend to trade-off decision accuracy against the effort. Thus, when decisions become complex, decision-makers shift toward using rules of thumb and noncompensatory procedures (that is, decision rules in which tradeoffs do not involve weighting of attributes) because their use is less costly than more complete quantitative approaches. The impetus toward less effortful strategies will strengthen when accurate predictions are hard to achieve and responsibility is difficult to apportion. Both of these conditions apply to stock evaluation, where return causality is difficult to estimate. Empirical studies have demonstrated that decision procedures become more intuitive or experiential the more reversible the decision, the more emotional the decision, and the greater the time stress. Therefore, the more reversible, emotional, or subject to time stress the trading in a stock is, the greater price volatility might be expected.

\section{Other Factors}

In addition to the specific behavioral factors of the capital market and investors, the exchange rate and the global price of gold are also important variables introducing many monetary and financial developments and are a basis for explaining policymakers in the orientations of monetary and exchange rate policies (Fotros and Hoshidari, 2017).

The effects that these vital indicators have on investors could be a model for important parts of the capital markets' behavior. The followings are the most important aspects of the effects of oil, currency and gold prices on the capital market. As the price of oil rises, foreign exchange from oil sales revenues is transferred to the foreign exchange reserve account. If there is not sufficient demand for currency at the target price, the central bank is forced to buy currency and turn it into Rial resources for the budget. This policy will increase the net foreign assets of the central bank and also the country's monetary base. In case of the reduction of the oil price, because the government does not reduce its expenditures, the budget deficit is created and the government will be forced to borrow part of it from the central bank. Thus the net debt of the government to the central bank will increase and this, in 
turn, strengthens the base of the national currency. Therefore, both in the case, a rise and fall in oil price, we can expect to see a jump in liquidity as a subsequent jump in the monetary base (Ebrahimi and Shokri, 2012). Increasing the money supply can be both a macro-level policy variable and a part of an individual's portfolio affecting the stock price index. When the money supply increases, people realize that they have more money than they need and they increase their spending and one of the markets in which they spend their money is the stock market. As a result of the increasing demand for stocks, their price increases. In other words, excess liquidity in the household basket to earn more profit and even protection of the value of money against inflation is attracted to the stocks market like other capital markets (gold, real state, etc market). The relationship between stock price and money can also be explained from the perspective of the basket assets. Assuming the balance of the money market as an asset in the portfolio, the individuals or firms try to maximize the return on their assets by creating diversity in the composition of asset maintenance and therefore, due to the substitution of assets and money in the portfolio of individuals, if the amount of money in this portfolio increases, the share of shares decreases. With the increase in stock demand and if the money supply does not change, the prices for stocks increase. This may be due to the fact that with increasing stock demand, one can expect price and stock returns increases, and if the money supply is unchanged, the interest rate (money price) will remain constant, and because investors seek to increase profits so are expected to hold more shares in their portfolio. Regarding the former, the relationship between stock prices and money supply is negative, while in the latter case the relationship is positive. So, in general, we cannot have a definite idea about the final effect of changes in the money supply on the stock price (Hasanzade and Kiavand, 2015).

The second channel is the impact of oil prices on stock prices through the currency effect. Given the fact that the money paid from oil revenues is in foreign currency, the rise in oil prices causes incomes and foreign exchange reserves to increase (resulting in the appreciation of the national currency against foreign currency). An increase in the exchange rate at one way can lead to an increase in income of exporters and subsequently, can increase their profits and share's price., increases their stock price (after demand) and on the other way, can lead to seeing a decreasing trend in profits and share's price of importer firms (Morley and Pentecost, 2000).

The third channel is the impact of oil prices on stock prices through the effect of expectations. With a rise in oil prices and consequently oil revenues in oil-exporting countries, optimistic expectations will be formed about the 
prosperity and increase of activities in the country's economy. The formation of these expectations will cause the companies listed on the stock exchange to increase their profitability so that the current value of the future cash flow and consequently the stock index will grow positively (Keshavarz Hadad and Manavi, 1999). It should be borne in mind that with the increase in oil prices, the cost of production will also increase for oil-dependent companies. This phenomenon may affect investors' decision to invest in a particular stock by influencing expectations, which leads to the reduction of demand and thus reduction of stock prices (Fotros and Hoshidari, 2017).

The fourth channel is the impact of oil prices on stock prices through the income effect. Higher oil prices mean the transition of wealth from oilimporting countries to oil-exporting countries. The effect of this price change depends on what the government does with the increase in revenue due to the increase in oil prices. If this increase in revenue is to purchase domestic goods and services, it can increase public wealth. Also with an increase in demand for labor and capital, it will create investment and business opportunities. Therefore, it has a positive effect on the future cash flow of firms. But, on the other hand, the rise in oil prices as one of the production inputs will mean an increase in costs and reducing firms' revenues and will have a negative effect on future cash flow, and as a result will lead to lower stock prices (Hasanzade and Kiavand, 2015).

Oil prices can also affect stock prices in oil-exporting countries through another channel called the return effect. Considering the fact that the rise in oil prices increases the cost of products produced by industrialized countries and because most oil-exporting countries are importers due to their inability and lack of technology to process crude oil, oil products and derivatives, this leads to an increase in the monetary value of imports and a negative effect on future cash flow for firms. In these countries, as a result, stock prices fall (Arouri and Fouquau, 2009).

The effects of oil prices on capital market expectations and financial behavior are created under the influence of changes in investors' risk expectations. With the rise in oil prices and consequently oil revenues in oilexporting countries, optimistic expectations about creating prosperity and increasing activities will be formed at the level of the country's economy. This issue may lead to some judgment biases and overconfidence errors, errors in the optimism of the economy and errors in extreme reactions to changes in oil prices, and under the influence of these behavioral factors, investors' 
expectations are created to increase the demand for buying and selling shares of the company.

In addition to dividends, stock buyers also pay attention to changes in the company's intrinsic value. Industries the creating and launching of which require the supply of machinery from abroad, their intrinsic value is affected due to changes in exchange rates. If a company imports machinery at low exchange rates, with the increase in exchange rates, the intrinsic value of the company will increase and this inherent increase is exacerbated when the establishment of a similar company is possible due to high exchange rates and if the company's products are exclusive, the demand for it will increase and the company's profit will increase over time accordingly. On the other hand, the share of depreciation cost of machinery in the cost of manufactured goods decreases (Fotros and Hoshidari, 2017). Taking into account the abovementioned cases by investors, the demand for the share of these companies has increased and this issue will increase the stock prices of these countries. In addition, if the exchange rate decreases over time, it will leave the opposite result for these companies (Ibrahim, 1999). Among other factors that should be considered is the combination of assets and foreign currency debts of the country. If the exchange rate increases and the number of foreign exchange assets of the company are more than its foreign exchange debt, the profit from foreign exchange actually increases the profit of each share and the stock price of these companies will increase. Also, if foreign currency liabilities exceed foreign currency assets, foreign exchange losses will actually reduce earnings per share and the stock prices of these companies will decrease (Mousae et al, 2010). In fact, due to the need to reflect exchange rate changes in the company's bills, an increase or decrease in this factor directly affects the profit and loss of the firm and consequently the financial performance of the company. These effects through changing inclinations and expectations of users of information, explain the path of demand and supply, buying and selling companies' shares.

The behavioral aspect of the effects of exchange rate fluctuations on the market is not direct, but it leads to the risk of devaluation of national currency and as a result, the general level of a price commensurate with it. These changes in the economy and capital markets are the behavioral biases of the investors seeking to maintain the value of their assets and may lead to behavioral biases caused by pessimistic or optimistic predictions.

Gold and changes in gold prices act as an alternative market for investment and the characteristics of this market that include returns and related risks can affect the incentives to invest in the stock market and thus the 
behavior of investors. In such a way that the increase in the price of gold, whether due to its international changes or due to changes in foreign currencies in Iran, has caused the outflow of stray economic resources into this market and in some cases may also lead to high returns proportionate to the level of risk it has to investors. Therefore, the boom in the gold market as an alternative stock market has led to the withdrawal of part of the capital from the stock market and will also affect the behavior of investors (Samadi et al, 2007).

Gold as a precious metal plays a major role in explaining monetary and banking policies and mainly as a support for the national currency and it is usually regarded as the backbone of the national currency and banknote printing. This important role of gold causes the value of gold to be increasing over time as compared to all currencies common in all markets of the world because the main reference value of all currencies is the amount of gold of the governments' central banks. Therefore, the psychological aspect of the effects of the price of gold, in addition to substitution as an investment market, can also be due to the power of gold in determining the monetary and banking policies of countries, this important role of gold causes the value of gold to be increasing over time as compared to all currencies common in all markets of the world. Gold prices convince the investors that their decisions should be made partly under the influence of changes in gold prices (Davarzade, 2010). This issue and the replacement of the gold market have caused judgmental and cognitive biases in the behavior of stock market investors in such a way that the information risk arising from the trend of changes in gold prices may convince the investors to leave the investment markets.

\section{Research Methodology}

\section{Foreign studies}

In a study, Yin and Feng (2018) investigated the need for investors' attention to oil markets to predict their return on investment. They stated that investors should pay special attention to changes in the oil market to ensure the prediction of their stock risk. They showed that improving the ability to predict changes in oil prices improves the ability to predict stock returns traded in the capital market. Also, paying attention to oil price fluctuations increases the investors' ability to achieve positive profits. The results also showed that the role of oil prices as a macroeconomic indicator in the capital has changed and this indicator is an explanatory indicator of future forecasts. In a study, Turgat and Faisal (2018) evaluated the effects of oil and gold prices on the Turkish stock market. They examined the effects of short-term and long-term changes 
in oil and gold prices through monthly data from January 1986 to November 2016 in the Istanbul Stock Market Index. They used the self-regression model with the intermittent distribution. The results showed that the price of gold on the stock market index has been negative and significant both in the short and long term and the effects of oil prices on the Istanbul stock market is both positive and significant in both the short and long term. In a study, Delgado et al. (2018) examined the relationship between oil prices, exchange rate fluctuations and the Mexican stock market. They studied the period from 1992 to 2017 using the vector autoregression model (VAR). The results showed that the exchange rate has adverse effects on the Mexican stock market and the decline in the exchange rate had led to expectations of an increase in index. Also, the consumer price index has a positive effect on exchange rate changes and negative effects on the overall market index shares in Mexico. The results also showed that changes in oil prices lead to lower exchange rate fluctuations and expectations, in particular, it strengthens exchange rate fluctuations and, consequently, the stock market index among investors.

Qadan and Namab (2018), in a study entitled Investor 'Behavior and Oil Prices', assessed the impact of oil price fluctuations on investors' behavioral patterns. The results of their parametric and nonparametric analysis showed that, firstly, behavioral patterns were able to predict the direction of movements of oil price fluctuations and based on this, they use the changes in oil prices for their forecasts in the capital market. An analysis was done by using monthly, weekly and daily data of Israeli stock companies for the period between 1986 and 2016 and the results showed that the behavioral fluctuations of investors are affected in 9 different patterns under the influence of changes in oil prices. The results also showed that the impact of oil on stock prices after 2000 was greater than the previous period in which investment in oil companies had grown significantly. In an article, Joo and Park (2017) examined the relationship between oil prices and the stock market and the effects of uncertainty using the conditional variance of the stock index and oil price returns. This study used the stock price index of the US, Japan, Korea, and Hong Kong from 1996 to 2015. The dynamic two-variable GARC model (DCC) was used to investigate the effects of variable uncertainty of oil prices on stock indices. The findings of this research show that there is a negative and significant relationship in some short periods over time. Wang et al (2017) examined the impact of oil price fluctuations on corporate investment in the Chinese economy. They also consider whether ownership affects the relationship. Their results show the impact of oil price fluctuations on corporate investment is negative, and this relationship is stronger in firms with state ownership than privately owned enterprises. 


\section{Domestic Studies}

In a study, Botshekan and Mohseni (2018) examined the overflow of oil price fluctuations on stock market returns. They state that today, addressing the issue of fluctuating overflow in different markets and their relationship with each other, in terms of their use in predicting shocks and crises is an important issue. Fluctuating overflow indicates the process of information transfer and after that capital flows between markets. This paper aims to investigate the dynamic conditional correlation and oil price fluctuation overflow on stock index returns using multivariate GARCH models including Baba, Parasite, Coroner and Kraft (BEKK), Fixed Conditional Correlation (CCC), DCC (Dynamic Conditional Correlation) and Model Multivariate GARCH (VARMA-GARCH) over a period of 12 years until the end of 2016. The purpose of this study is to participate in identifying the impact of external shocks as important as oil on the efficiency of the stock index for using in managing financial fluctuations, investment decisions and risk management. The results of this research confirm the existence of conditional correlation in short-term fluctuations and the existence of oil price overflow effects on the stock market index.

In an article, Jafari (2016), evaluated the effect of oil price fluctuations on investment behavior in the Iranian economy: the application of the Markov Switching Model. His goal was to examine the nonlinear effects of OPEC oil price fluctuations on investment decisions during the period $1983-2015$ for Iran's economy as a country rich in oil resources. To achieve this purpose, the Markov Switching Model was used and oil price fluctuation was used using the EGARCH model. The results of model estimation, using the fixed probability function (FTP) method, indicate that the effect of oil price fluctuations on behavior investment can be divided into two regimes. In such a way that in both regimes, the uncertainty caused by changes in oil prices leads to reduced investment but its effects are not the same in the two regimes. So the uncertainty caused by oil prices has asymmetric effects on investment decisions. In the meantime, sanctions imposed by the US government have had a negative effect on investment against the Iranian economy. The results also showed that the financial crisis in 2008 has not affected investment decisions in the Iranian economy. These results can provide important information for governments and economic enterprises intending to make capital policies and decisions.

\section{Research methodology and findings}

Volatility forecasting is crucial for any investment decisions, such as asset allocation and risk management. This paper tries to analyze asymmetric and 
fractionality as a factor of behavioural finance on volatility forecasting of a stochastic process, highlighting the importance of incorporating these effects into the forecasting model itself. Moreover, a methodology for separating realized volatility into daily variances is introduced. Asymmetries and memory properties in the data-generating process for asset returns are known stylized facts. The existence of these effects poses challenges for obtaining accurate volatility forecasts and requires models that can take into account all of those empirical features.

The simplest model differs from the ARCH model in that it incorporates squared conditional variance terms as additional explanatory variables. This allows the conditional variance to follow an ARMA process. If we write the residual as:

$u_{t}=v_{t} \sigma_{t}^{2}=v_{t} \sqrt{h_{t}}$

Where $\sigma_{t}^{2}$ is written as $h_{\mathrm{t}}$ and $v_{\mathrm{t}}$ have a zero mean and variance of one? We can then write the conditional variance as:

$h_{t}=\alpha_{0}+\sum_{i=1}^{q} \alpha_{i} u_{t-i}^{2}+\sum_{i=1}^{p} \beta_{i} h_{t-i}$

as mentioned, Among the many possible competing univariate GARCH models, one of the most interesting groups allows for the presence of the socalled asymmetry or leverage effect. In our view, asymmetry and leverage are two distinct phenomena, both inspired by the seminal work of Black in 1976. He observed that "when things go badly for the firm, its stock price will fall, and the volatility of the stock will go up. When things go well, the stock price will rise and the volatility of the stock will go down. A negative return will be tied to a rise in volatility, and a positive return will be tied to a fall in volatility." Translating this quotation into volatility modeling, $\varepsilon_{t}=r_{t}=\mu>0$ $>0$ will reduce the volatility and $\varepsilon_{\mathrm{t}}<0$ will increase it. Also with estimates, structure and pattern of conditional variance can be identified except power and finally, the existence of long-term memory is testable in fluctuations. FIAPGAHAR-X models are used in this article to address these. Tsy (1998) introduced a very flexible model for a conditional variance by combining the FIGARCH model developed by Bailey et al. (1993) and the asymmetric PARCH model introduced by Ding et al. (1993). In this model, the asymmetric effect of shocks on variance is distinguishable. The FIAPARCH (q, d, p) can be seen as follows: 
Mean equation: $\quad y_{t}=\alpha y_{t 1}+\varepsilon_{t-1}$

Variance equation: $=\boldsymbol{\omega}+\{\mathbf{1}-[\mathbf{1}-\boldsymbol{\beta}(B)]-\mathbf{1} \boldsymbol{\varphi}(B)(\mathbf{1}-B) \boldsymbol{d}\}\left(\left|\boldsymbol{\varepsilon}_{\boldsymbol{t}}\right|-\boldsymbol{\gamma} \boldsymbol{\varepsilon}_{t}\right)$

Where $\gamma$ is the lever effect and $\delta$ is the power of the pattern. When $\mathrm{d}=0$, the FIAPARCH pattern becomes the PARCH pattern. Especially FIAPARCH model provides flexibility for conditional second torque modeling which considers long-term memory property, return predictability structure oscillations and the asymmetric nature of oscillations (i.e. lever effects).

This developed model also deals with the number of variables included in the model and also has fewer limitations compared to other multivariate fluctuation models such as the full BEKK-GAREH and VEC-GARCH models. the assumption of the return of fluctuations in this study can be described in the AR Model, where the dynamics of current stock returns (present) is shown by its initial break and shock or the return of a past break-in other markets $x t-1$ as follows:

$$
(1-£) t=\mu+x t-1+\varepsilon t, t \in, \varepsilon t=Z t \sqrt{h t}
$$

Where $|\mu| \in[0, \infty),|£|<1$ and $\{\mathrm{Zt}\}$ have a T-student distribution $(\mathrm{Zt} \sim \mathrm{ST}(0$, $1, v)$ ). Also the ht conditional variance is a positive probability.

The FIAPARCH model has the feature that enhances the flexibility of the conditional variance specification by the following:

1) Asymmetric reaction of conditional fluctuations to positive fluctuations and negative shocks (that are able to track the effect of leverage).

2) The data for determining the power of return to see whether the predictable structure in the volatility pattern is strong or not

3) Long-term memory in fluctuation dependence, hinges on the integrated downtrend or d parameter difference (Bailey et al., 1996)

These features in asset yield fluctuation processes imply asset allocation, optimal portfolio design and portfolio diversification benefits (Conrad et al., 2011)

It is also noteworthy that the FIAPARCH model includes two main categories of the ARCH type: APARCH and FIGARCH models. The FIGARCH model (p, d, q) by Bailey et al. (1996) is as follows:

$$
h_{t}=\omega|1-(L)|-1+[1-|1-\beta(L)|-1 \varphi(L)(1-L) d] \varepsilon_{t}^{2}
$$

Where $\mathrm{W}$ (the trend mean), $\beta$ (GARCH parameter), in $\varphi$ (finite range of polynomial intervals) and $\mathrm{d}$ (fractional difference parameter for long-term 
memory) are parameters that are estimated, while $0 \leq \mathrm{d} \leq 1$ and $\mathrm{L}$ represent the delay operator. The FIGARCH model provides more flexibility for conditional variance modeling and can differentiate between the stable covariance, the GARCH model when $\mathrm{d}=0$ and the non-stable IGARCH model when $\mathrm{d}=1$, while if $0<\mathrm{d}<1$ is flexible enough the FIGARCH Model will allow an average range of stability.

The RIAPARCH Model is a format of FIGARCH Model which adds the statement $\delta(\lambda \varepsilon t-|\varepsilon t|)$ to it which is stated as follows:

$h_{1}=\omega|\mathbf{1}-(L)|-\mathbf{1}+[\mathbf{1}-|\mathbf{1}-(L)|-\mathbf{1} \varphi(L)(\mathbf{1}-L) d]\left(\left|\varepsilon_{t}\right|-\lambda \varepsilon_{t}\right) b$

Where $\delta$ the term return power is for a predictable structure in the continuation of instability, it accepts positive values and it is used to empower them which increases h1 i standard deviation mean to the power of $\delta$ i when $\lambda>0$ implying that negative shocks will lead to higher conditional fluctuations than positive shocks. The opposite holds true if $\lambda<0$ FIGARCH Model is better than FIAPARCH Model for detecting asymmetry and long-term memory in conditional fluctuations.

As an attempt to assess the effects of overflow between different markets and the Iranian stock market, multiple models of FIAPARCH is introduced. The method developed by Engle (2002) is used for the conditional correlation structure. This model not only allows the correlation of temporal variables to be checked in sample markets but assures the positivity of the $\mathrm{H}$ variancecovariance matrix when constraints are imposed on the parameters.

In the general multi-variable model which is used, the variance-covariance residue matrix is defined as follows:

$H_{t}=D_{t} R_{t}$

where $\mathrm{D}$ the diagonal $(\mathrm{N} \times \mathrm{N})$ is the conditional standard deviation of residue which has been achieved from the second root of conditional variance of the AR (1) - FIAPARCH (1, d,1)(univariate model 1,d,1). Besides, Rt is a temporal conditional correlation matrix variable which is defined as follows:

$R_{t}=t(\rho i j)=,\left(\left(Q_{t}\right)\right)-2 Q_{t}\left(\operatorname{diag}\left(Q_{t}\right)\right)$

where $\mathrm{Q}_{t}$ is a positive matrix symmetric with the $(\mathrm{N} \times \mathrm{N})$ dimensions which are dependent on the squared standard residue of $u_{i, t}=0,1,2, \ldots T$. The unconditional variance-covariance matrix $\mathrm{Q}_{\mathrm{t}}$

depends on its intervals according to the following relation: 


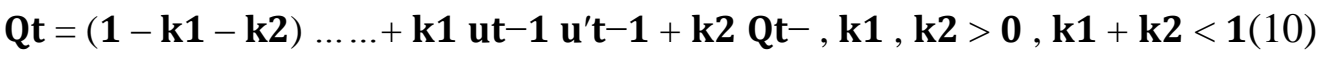

The variance-covariance matrix of $(\mathrm{N} \times \mathrm{N})$ equals $u_{i, t}=\frac{\varepsilon_{i, t}}{\sqrt{h_{i, t}}}$

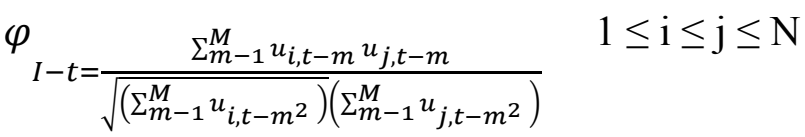

where the $u_{i, t}$ is the calculated standard residue from the univariate residue of the AR (1) -FIAPARCH $(1, \mathrm{~d}, 1)$ Model.

It is possible to extract the correlation coefficient between the other markets and stock markets of Iran in the time of $t$ based on 5 and 6 equations as follows:

$\rho_{12, t}=\left(1-K_{1}-K_{2}\right) \rho_{12, t}+K_{2} \rho_{12, t}+K_{1} \frac{\sum_{m-1}^{M} u_{i, t-m} u_{j, t-m}}{\sqrt{\left(\sum_{m-1}^{M} u_{i, t-m^{2}}\right)}\left(\sum_{m-1}^{M} u_{j, t-m^{2}}\right)}$

FIAPARCH model parameters are estimated using maximum likelihood (QML) method estimation according to log-likelihood function is given based on the following equation in two steps.

$I_{t}(\theta, \varphi)=-\frac{1}{2}\left[\sum_{t=1}^{\tau}\left(n \log (2 \pi)+\log \left|D_{t}\right|^{2} \varepsilon_{t} D_{t}^{-2} \varepsilon_{t}\right)+\sum_{t=1}^{\tau}\left(\log \left|D_{t}\right|+\right.\right.$ $\left.u^{\prime}{ }_{t} C_{t}^{-1} u_{t}-u_{t}-u^{\prime}{ }_{t} u_{t}\right)$

Finally, in the first step, a univariate $(1, d, 1)$ FIAPARCH model is determined for each of the return series, and ith estimations are obtained. In the second step, the parameters estimated from the first step are used to calculate the DCC. The next section discusses the data and estimation results.

\section{Research Findings}

The statistical population of the present article is the stock exchange which is extracted from the sample with daily frequency from the Stock Exchange Return Index from 2008 to September 2018. Accordingly, first, the stationary test and conditional variance heterogeneity have been performed on the total yield of the range, currency, gold and oil. The results showed all variables are stationary except the price index. Based on this, a test was conducted on the price index variable, the stationary test in the first-order changes showed that this variable is also stationary. In the results section, it is slightly expressed. Figure 1 illustrates the process of the trend of variables. Should be noted that 
since the scale of variables is different. Rescale dollar, gold and oil price such be clear to discuss the variable's trends.

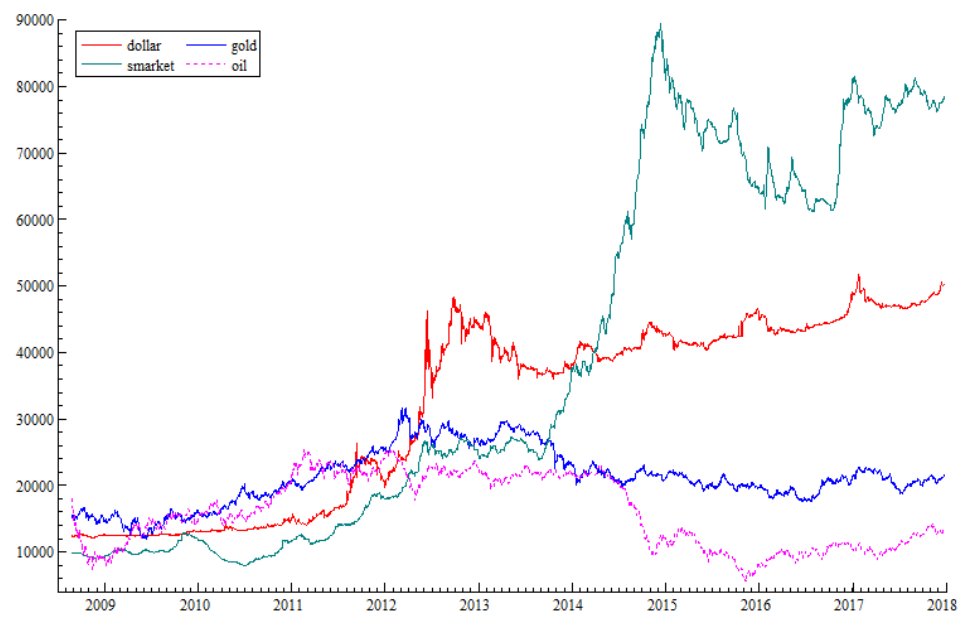

Figure 1. The level of variables

As can be seen from the above Figure, a positive correlation between the exchange rate and the stock market index can be imagined. This relationship shows that with the increase of the exchange rate, we can expect the profitability of the large stock firms as well as other export firms to increase, also this will increase the stock price of these stocks, and as a result, with a lag, the stock market index will increase. The Figure also shows that in the period under study, there is a negative correlation between the price of gold and the stock index, which according to portfolio theory, this relationship seems logical. Since investors are always seeking to increase their profits, by increasing the stock market index, they try to enter more of their capital into the stock market, and this leads to an increase in demand and an increase in the stock market index. In examining the relationship between oil and the stock market index, the period before and after the outbreak of coronavirus can be divided into more detailed studies. As can be seen from Figure 1, in the period before the coronavirus outbreak, there is a positive correlation between the oil price trend and the stock market index, which is consistent with the argument expressed in the previous sections. But in the aftermath of the coronavirus outbreak, this correlation has become somewhat weaker and even negative. This relationship can be due to the fact that in the mentioned period, mainly what caused the increase in the stock market index was the high inflow of liquidity to the stock market, and accordingly, despite the decrease in oil prices 
due to demand due to the inflow of liquidity, the stock market index increased. Figure 2 shows the return of variables. As can be seen from the figure below, all variables fluctuate around the zero return trend and fluctuations in the trend of variables can be witnessed, which indicate that important information can exist in variance conditional return of variables.
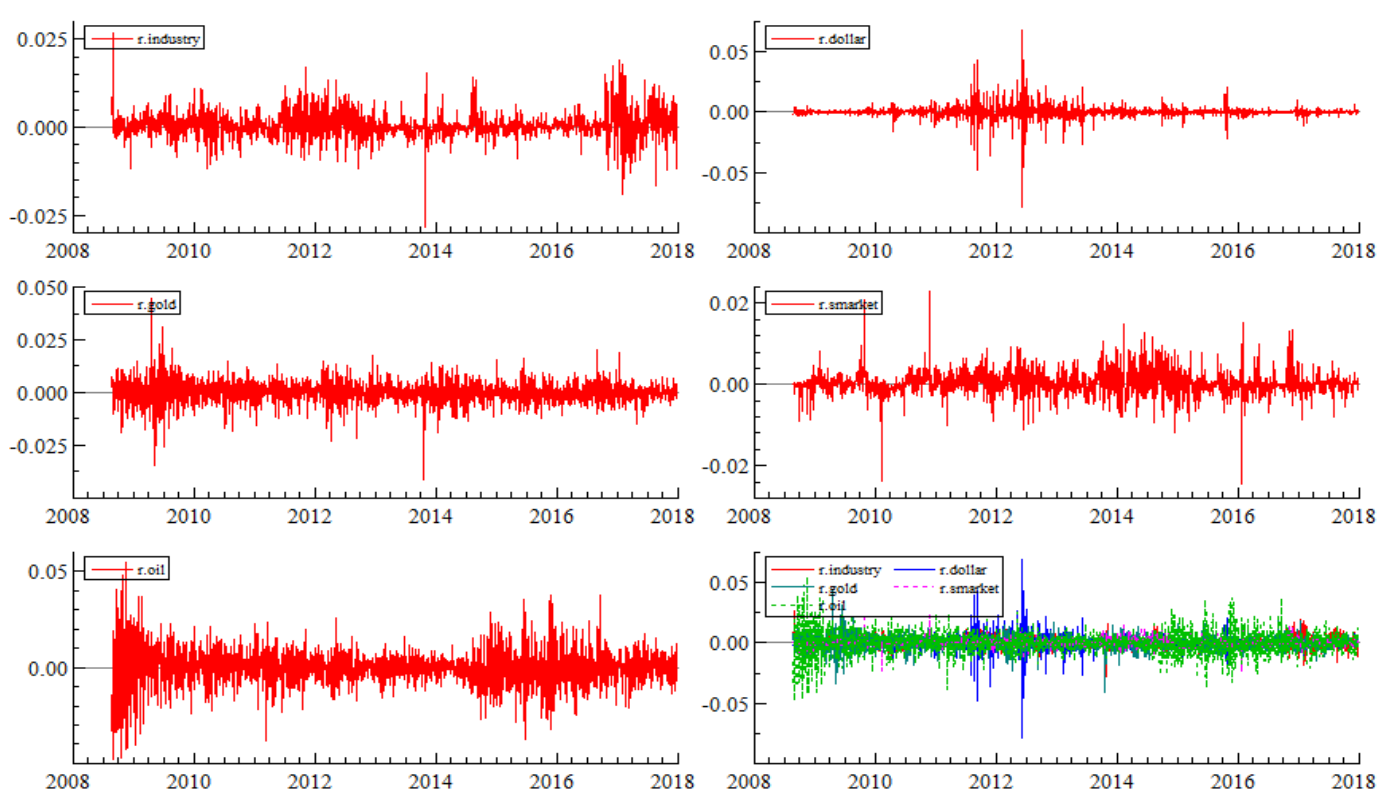

Figure 2 . The return of variables

The existence of spillover effects between markets is discussed in two ways. To check turbulence transmission in markets, the F statistic can be used as follows:

There are no double effects on markets: $\mathrm{H} 0: \mathrm{aij}=0, \mathrm{i}, \mathrm{j}=1,2,3,4 \& \mathrm{i} \neq \mathrm{j}$

The effects of overflow in the markets are twofold: $\mathrm{H} 1: a i j \neq 0, \mathrm{i}, \mathrm{j}=1,2,3,4 \&$ $i \neq j$ 
Table 1. F test results to investigate the effects of turbulence overflow

\begin{tabular}{|c|c|c|c|}
\hline Test & Null hypothesis & F statistics & P_Value \\
\hline $\begin{array}{c}\text { Existence of effects } \\
\text { currency overflow and } \\
\text { ARCH stock }\end{array}$ & $\mathrm{H} 0: a_{12}=a_{13}=\ldots=a_{32}=0$ & 14,39 & 0,000 \\
\hline $\begin{array}{c}\text { Existence of effects } \\
\text { oil spill and } \\
\text { ARCH stock }\end{array}$ & $\mathrm{H} 0: a_{12}=a_{13}=\ldots=a_{32}=0$ & 6,82 & 0,009 \\
\hline $\begin{array}{c}\text { Existence of effects } \\
\text { gold overflow and } \\
\text { ARCH stock }\end{array}$ & $\mathrm{H} 0: a_{12}=a_{13}=\ldots=a_{32}=0$ & 11,57 & 0,000 \\
\hline
\end{tabular}

The results of the F-test to check the zero non-linear coefficients of matrices A and $G$, which are presented in Table 1 . indicate the rejection of the null hypothesis of the nonlinear coefficients of matrices of A and G. As a result, the effects of shocks on the turbulence are meaningful between all markets with the stock market and the research hypothesis claiming the transfer of turbulence in the markets to the stock market is confirmed.

In estimations, the conditional mean equation intervals are designated based on information criteria Akaik (AIC) and Schwarz-Bayesian (SBC) except for the $\mathrm{ARCH}$ and GARCH conditional variance equation. This approach is followed in accordance with the Box-Jenkins' diagnostic method. Also, the distribution under consideration is regarded as a t-distribution. The t-distribution is comparable to the normal distribution of comprehensiveness and has more flexibility and these distributions are almost compatible in large sample sizes and according to the AIC criteria and SBC, the FIAPIARCH pattern estimation process leads to two types of patterns associated with the interval under study. Also, the selection of the optimal model based on the criteria of specification tests indicates the lack of self-correlation and the presence of significant information in the residues. 
Table 2. Estimation of ARMA $(1,0)$-FIAPARCH-X $(1, d, 1)$ Model for efficiency model

\begin{tabular}{|c|c|c|c|c|c|c|c|c|c|}
\hline $\begin{array}{c}\text { Equati } \\
\text { on } \\
\text { Varian } \\
\text { ce } \\
\text { Conditi } \\
\text { onal } \\
\text { efficie } \\
\text { ncy }\end{array}$ & $\operatorname{AR}(1)$ & $\begin{array}{c}\mathrm{d} \\
\text { Figarc } \\
\mathrm{h}\end{array}$ & $\mathrm{ARCH}$ & $\begin{array}{c}\text { GARC } \\
\mathrm{H}\end{array}$ & $\begin{array}{c}\text { PARC } \\
\mathrm{H}\end{array}$ & $\begin{array}{c}\text { APGAR } \\
\text { CH } \\
(\lambda)\end{array}$ & gold & $\begin{array}{l}\text { Exchan } \\
\text { ge rate }\end{array}$ & oil \\
\hline & $\begin{array}{l}\cdot,+\varphi \wedge \\
(\cdot, \cdots)^{*}\end{array}$ & $\begin{array}{c}0.4817 \\
)^{*} \\
\cdot, \cdot+\cdot \\
(\end{array}$ & $\begin{array}{c}\cdot,)^{\prime K r} \\
)^{* *}, \cdot, \leq \varepsilon\end{array}$ & $\begin{array}{c}\cdot, r \cdot r \\
)^{* *} \\
(\cdot, \cdot r V\end{array}$ & $\begin{array}{c}1, \sum \wedge q \\
* * * \\
, \cdots r) \\
(\end{array}$ & $\begin{array}{l}-\cdot, 10 r \\
* * * * \\
(\cdot, \cdot r \varepsilon)\end{array}$ & 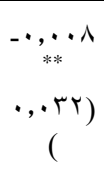 & $\begin{array}{c}{\stackrel{\cdot}{*} Y_{0}} \\
(\cdot, \cdots \wedge)\end{array}$ & 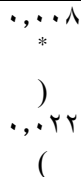 \\
\hline $\begin{array}{c}\text { Accura } \\
\text { cy } \\
\text { Logarit } \\
\mathrm{hm}\end{array}$ & $\begin{array}{c}\mathrm{Li}^{-} \\
\text {McLeo } \\
d^{2} \\
(20)\end{array}$ & $Q\left(20^{2}\right)$ & & & & & & & \\
\hline $\begin{array}{c}29735 . \\
0228\end{array}$ & Y^,१ & $9 \varepsilon, .7$ & & & & & & & \\
\hline
\end{tabular}

Considerations: * ** and $* * *$ show significance at the level of probability 1 , $5 \%$ and $10 \%$, respectively. Numbers below computational parameters are their standard deviation

Figure 3 shows the results of spillover between markets. The effects of overflow between markets are mentioned in two ways. In these subfigures, the net effects of overflows between markets are examined in a binary comparison. The horizontal axis shows the periods on a daily basis and the horizontal axis shows the net amount of the effects of overflow fluctuations. If the chart falls below zero, it indicates the positive effects of the overflow of fluctuations of the first market on the second. In other words, it can be argued that fluctuations in the first market have caused fluctuations in the secondary market. The following are the results of the overflow effects on other markets in general. Each of the forms shows that it has been dominant or defeated in front of other markets in the form of fluctuations in the capital market. If the value of the chart is above the zero line, it indicates dominance over other markets and vice versa. In other words, if the high volume of the chart is positive, it can be stated that in that period of the market, it has been able to play an important 
role in the capital market in shaping fluctuations compared to other markets, and market fluctuations cause fluctuations in other markets. will be.

Figure 3. volatility spillover of markets
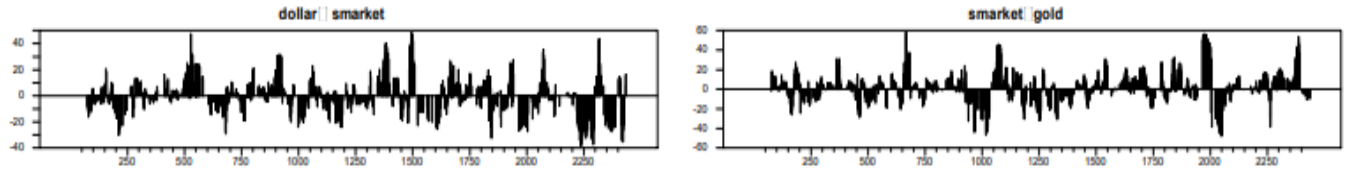

dollar industry
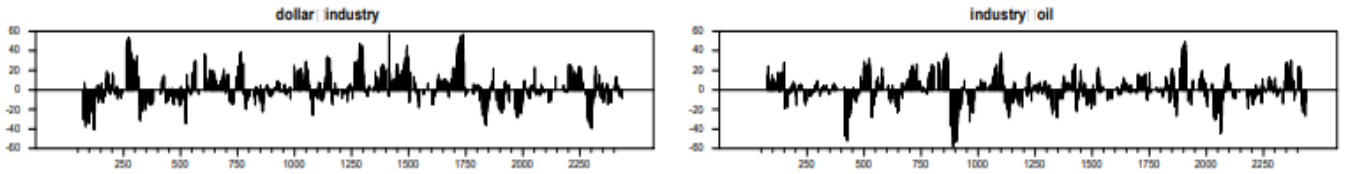

dollar oil
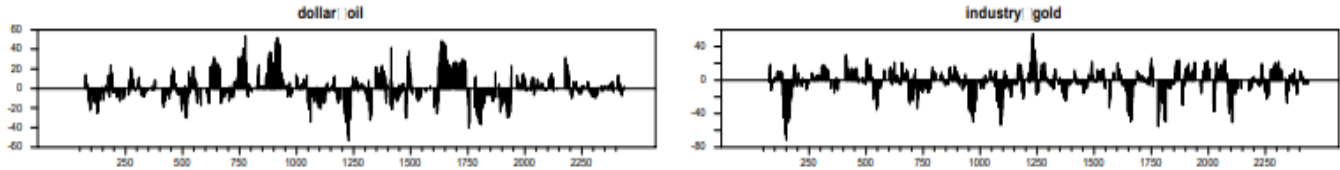

dollar gold

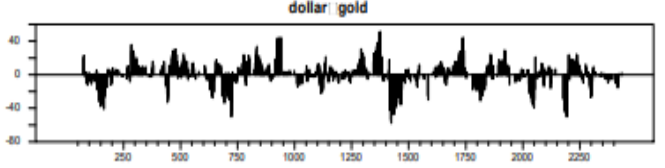

oll / gold
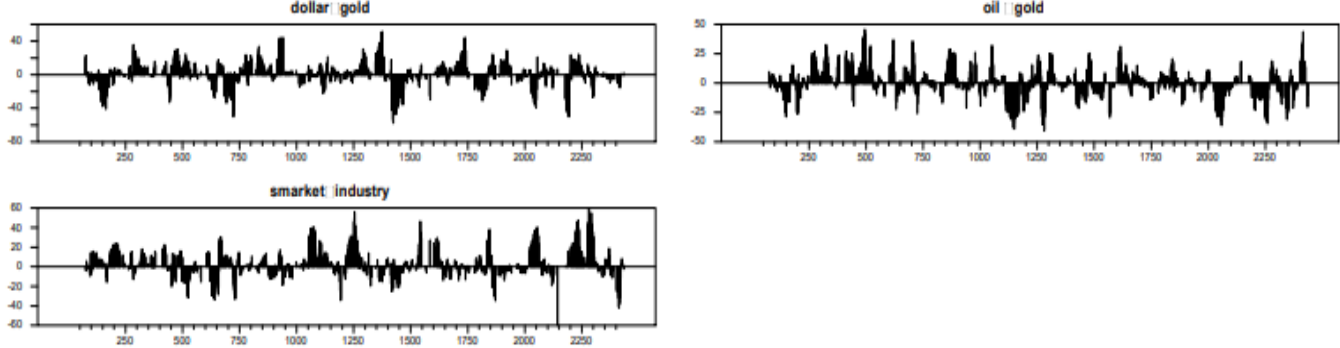

smarket oil

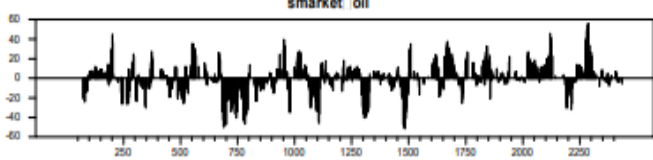

According to the results, it was expected that if the market fluctuates among investors and the resulting excitement could lead to the outflow of liquidity and the entry of speculators into the gold and foreign exchange market due to the dominance of the stock market over gold and foreign exchange. The results showed that the stock market has a more colorful role in shaping capital market fluctuations than other markets and has been able to capture most of the fluctuations and excitement between the foreign exchange, gold and energy markets. To attract. It can also be stated that if liquidity leaves the stock market, it can cause other markets to fluctuate sharply. 


\section{Conclusion}

With the expansion of industrial and economic activities and the need of companies for financial resources, the role of the capital market and its symbol, the stock exchange, has become clearer than ever in directing capital. The Optimal allocation of financial resources concerning stock market efficiency concerns the correct pricing of stocks. The investors, in addition to considering many financial and non-financial factors inside and outside the company for forecasting and decision making, by being aware of the factor affecting stock returns, can determine the stock price behavior more carefully and therefore make more effective decisions. In the investment decision process by investors, using macroeconomic indicators and analyzing its changes, are some of the important factors for decision-making and predicting stock returns. This paper uses the ARIMA (1,0, and 0) -FIAPARCH Model to investigate investor behavior in the stock market with an emphasis on control variables of oil, gold and currency. The results showed that the effect of the currency ratio has been due to two other factors. Finally, the results of model estimation showed that behavioral biases are also verifiable with respect to the effects of asymmetric fluctuations.

\section{Declaration of Conflicting Interests}

The authors declared no potential conflicts of interest concerning the research, authorship and, or publication of this article.

\section{Funding}

The authors received no financial support for the research, authorship and, or publication of this article.

\section{References}

Abolafia, Mitchel. 1996. Making Markets: Opportunism and Restraint on Wall Street. Cambridge, MA: Harvard Press. Anand, Paul. 1993. Foundations of Rational Choice under Risk. New York: Oxford Press

Arouri, M. E. H., \& Fouquau, J. (2009). On the short-term influence of oil price changes on stock markets in GCC countries: linear and nonlinear analyses. ArXiv preprint arXiv: 0905.3870. 
Baillie, Richard \& Han, Young-Wook \& Myers, Robert. (2007). Long Memory and FIGARCH Models for Daily and High-Frequency Commodity Prices. Queen Mary, University of London, School of Economics and Finance, Working Papers

Bauman, W. Scott. 1967. "Scientific Investment Analysis: Science or Fiction?" Financial Analysts Journal, vol. 23, no. 1 (January/ February):93-97.

Botshekan, M., Mohseni, H. (2018). Investigation volatility spillovers between oil market and stock index return. Journal of Investment Knowledge, 7(25), 267284.

Conrad, D., Keebler, J., DePristo, M. et al. Variation in genome-wide mutation rates within and between human families. Nat Genet 43, 712-714 (2011).

Ding Zhuanxin, Clive W.J. Granger, Robert F. (1993) Engle, A long memory property of stock market returns and a new model, Journal of Empirical Finance, Volume 1, Issue 1,1993, Pages 83-106.

Ebrahimi, M., shokri, N. (2012). Asymmetric effects of oil price shock on the stock price index: Comparison of the bootstrap confidence interval in impulse response function. Journal of Applied Economics Studies in Iran, 1(2), 115-144.

Engle, R. (2002) Dynamic Conditional Correlation: A Simple Class of Multivariate Generalized Autoregressive Conditional Heteroskedasticity Models. Journal of Business \& Economic Statistics, 20, 339-350.

Fotros, M., Hoshidari, M. (2017). The number of influence fluctuations in the price index of Tehran Stock Exchange and Dubai fluctuations in oil prices (WTI). Journal of Applied Economics Studies in Iran, 6(22), 171-195.

Hammond, Kenneth. 1990. The Integration of Research in Judgment and Decision Theory. Boulder, CO: University of Colorado.

Hribar, P., McInnis, J.M. (2012). Investor sentiment and analysts' earnings forecast errors, management science. Special Issue on Behaviorial Economics and Finance, 58(2), 293-307.

Jafari, M. (2016). The Effect of Oil Price Volatility on Investment Behavior in Iran: An Application of Markov-Switching Model. Quarterly Journal of Economic Growth and Development Research, 8(32), 110-95.

Ibrahim, M.H. (1999), "Macroeconomic Variables and Stock Prices in Malaysia: An Empirical Analysis", Asian Economic Journal, Vol. 13, PP. 219-231.

Joo, Y. C., \& Park, S. Y. (2017). Oil prices and stock markets: Does the effect of uncertainty change over time? Energy Economics, 61, 42-51.

Keshavarz Hadad GH.R., Manavi S.H, (2009), stock market and exchange rates interactions with respect to shocks, IRANIAN ECONOMIC RESEARCH, winter 2009, Volume 10, Number 37; Page(s) 155 To 177. 
Libo, Yin and Hiabao, Feng. (2018), "Can investors attention on oil markets predict stock returns?" The North American Journal of Economics and Finance, Available online 25 August 2018.

Lili and Zvliv f.Hv. (1998). Responses of the Stock Market to Macroeconomic Announcements across the Economic States IMF Working Paper (93-97).

Mahmoud, Qadan and Hazar, Namab. (2018), "Investor sentiment and the price of oil”, energy economics, Vol. 69, January, pp 42-58.

Morley, B., \& Pentecost, E. J. (2000). Common trends and cycles in G-7 countries exchange rates and stock prices. Applied Economics Letters, 7(1), 7-10.

Mousaei et al (2010), The correlation between the stock market and macro economical variables, Journal of Economic Research and Policy, N54, P73-94.

NancyAreli Bermudez Delgado., EstefaníaBermudez Delgado and EduardoSaucedo. (2018) The relationship between oil prices, the stock market and the exchange rate: Evidence from Mexico, The North American Journal of Economics and Finance, ISSN: 1062-9408, Vol: 45, Page: 266-275.

Odean, T. (1998b). Are investors reluctant to realize their losses? Journal of Finance, 53 (5), 1775-1798.

Odean, T. (1999). Do investors trade too much? American Economic Review, 89 (5), $1279-1298$

Olsen. A. Robert. Behavioral Finance and Its Implications for Stock-Price Volatility. Financial Analysts Journal, Vol. 54, No. 2 (Mar. - Apr. 1998), pp. 10-18

Payne, John W. 1993. The Adaptive Decision Maker. Cambridge, United Kingdom: Cambridge Press.

Peters, Edgar. 1994. Fractal Market Analysis: Applying Chaos Theory to Investment and Economics. New York: John Wiley \& Sons.

Pumpin, Mishlam. (2009). Behavioral Financial Knowledge and Asset Management, translated by Dr Ahmad Badri, Kayhan Publishing Company.Produce Better Investment Outcomes". Journal of Wealth

Schwartz, Robert A. 1988. Equity Markets: Structure, Trading and Performance. New York: Harper Business.

Shefrin, H., and Statman, M., (1985). The disposition to sell winners too early and ride losers too long: theory and evidence. Journal of Finance, 40 (3), 777-790.

Shiller.J. Robert. (2003). From Efficient Markets Theory to Behavioral Finance. Journal of Economic Perspectives-Volume 17, Number 1-Winter 2003Pages 83-104

Subair, K., \& Salihu, O. M. (2010). Exchange Rate Volatility and the Stock Market: 
The Nigerian Experience. Kwara StateUniversity.

Shefrin, Hersh. (2001). Behavioral Finance The International Library of Critical Writings in Financial Economics series. V I through IV. Cheltenham, U.K. Edward Elgar.

Simon. Herbert A. (1987). Making Management Decisions: The Role of Intuition and Emotion. Academy of Management PerspectivesVol. 1, No. 1

Turgut., tursoy and Faisal., Faisal. (2018), "The impact of gold and crude oil prices on the stock market in Turkey: Empirical pieces of evidence from ARDL bounds test and combined cointegration" Resources Policy, Vol 55, March 2018, Pages 49-54

Wang, Y., Xiang, E., Cheung, A. W. K., Ruan, W. \& Hu. W. (2017). "International Oil Price Uncertainty and Corporate Investment: Evidence from China's Emerging and Transition Economy". Energy Economics, 61, 330-339.

White, Eugene. 1990. Crashes and Panics: The Lessons from History. Homewood, IL: Irwin One.

\section{Bibliographic information of this paper for citing:}

Goudarzi, Mahmoud; Mohammadzadeh, Amir \& Seighali, Mohsen (2022). Investigation of the Effect of Behavioral and Macroeconomic Factors on the Volatility of Tehran Stocks Market: FIAPGARCH-X. Iranian Journal of Finance, 6(1), 28-53.

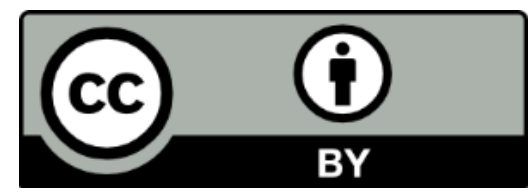

